\title{
Synthesis and Photocatalytic Activity of Mo-Doped $\mathrm{TiO}_{2}$ Nanoparticles
}

\author{
Ji-guo Huang, ${ }^{1}$ Xue-ting Guo, ${ }^{1}$ Bo Wang, ${ }^{1}$ Lin-yang Li, ${ }^{1}$ Mei-xia Zhao, ${ }^{1}$ Li-li Dong, \\ Xing-juan Liu, ${ }^{1}$ and Yu-ting Huang ${ }^{1}$ \\ ${ }^{1}$ Key Laboratory of Groundwater Resources and Environment, Ministry of Education, Jilin University, Changchun 130026, China \\ ${ }^{2}$ Key Laboratory of Songliao Aquatic Environment, Ministry of Education, Jilin Jianzhu University, Changchun 130118, China \\ ${ }^{3}$ School of Environment, Northeast Normal University, Changchun 130117, China \\ Correspondence should be addressed to Li-li Dong; donglili101@sina.cn
}

Received 25 November 2014; Accepted 23 December 2014

Academic Editor: Eugen Culea

Copyright (C) 2015 Ji-guo Huang et al. This is an open access article distributed under the Creative Commons Attribution License, which permits unrestricted use, distribution, and reproduction in any medium, provided the original work is properly cited.

\begin{abstract}
The undoped and $\mathrm{Mo}$-doped $\mathrm{TiO}_{2}$ nanoparticles were synthesized by sol-gel method. The as-prepared samples were characterized by X-ray diffraction (XRD), diffuse reflectance UV-visible absorption spectra (UV-vis DRS), X-ray photoelectron spectra (XPS), and transmission electron microscopy (TEM). The photocatalytic activity was evaluated by photocatalytic degradation of methylene blue under irradiation of a $500 \mathrm{~W}$ xenon lamp and natural solar light outdoor. Effects of calcination temperatures and Mo doping amounts on crystal phase, crystallite size, lattice distortion, and optical properties were investigated. The results showed that most of $\mathrm{Mo}^{6+}$ took the place of $\mathrm{Ti}^{4+}$ in the crystal lattice of $\mathrm{TiO}_{2}$, which inhibited the growth of crystallite size, suppressed the transformation from anatase to rutile, and led to lattice distortion of $\mathrm{TiO}_{2}$. Mo doping narrowed the band gap (from $3.05 \mathrm{eV}$ of $\mathrm{TiO}_{2}$ to $2.73 \mathrm{eV}$ of $\mathrm{TiMo}_{0.02} \mathrm{O}$ ) and efficiently increased the optical absorption in visible region. Mo doping was shown to be an efficient method for degradation of methylene blue under visible light, especially under solar light. When the calcination temperature was $550^{\circ} \mathrm{C}$ and the Mo doping amount was $2.0 \%$, the Mo-doped $\mathrm{TiO}_{2}$ sample exhibited the highest photocatalytic activity.
\end{abstract}

\section{Introduction}

Titanium dioxide $\left(\mathrm{TiO}_{2}\right)$ has been considered as one of good photocatalysts due to its excellent properties such as low cost, nontoxicity, chemical stability, and high photocatalytic activity [1-6]. However, $\mathrm{TiO}_{2}$ only becomes active under irradiation with ultraviolet (UV) light (3-4\% of the solar energy) because of its wide band gap $(3.2 \mathrm{eV})$, and visible portion (approximately 45\%) cannot get used effectively [7]. Therefore, it is a critical issue to reduce the band gap of $\mathrm{TiO}_{2}$ for making it photosensitive to visible light. The enhancement of optical absorption in visible region will improve the photocatalytic efficiency of $\mathrm{TiO}_{2}$, which may promote the utilization of the solar light. In the last decade, great efforts have been made to modify the band gap of $\mathrm{TiO}_{2}$. These results show that metal ion doping is one of the effective ways. At present, the investigations about doping elements mostly focus on transition metal ions doping [8-11]. Transition metal ions modify microstructures and electronic structures of $\mathrm{TiO}_{2}$ and increase its photocatalytic efficiency. Molybdenum $(\mathrm{Mo})$ is a transition metal and its doping into $\mathrm{TiO}_{2}$ can shift the absorption edge towards visible region, increase the absorption under both UV and visible light, and enhance the photocatalytic activity of $\mathrm{TiO}_{2}[12-15]$. However, due to the large number of possible variations, it is not simple to find out the optimum doping amount and calcination temperature at the same time. Besides, obtaining optimum photocatalysts to function under solar light is very meaningful.

In this work, we successfully prepared Mo-doped $\mathrm{TiO}_{2}$ nanoparticles by sol-gel method. The effects of doping amount and calcination temperature on the photocatalytic activity of photocatalysts were studied. Structure characteristics characterization and analysis of as-prepared samples were studied by XRD, UV-vis DRS, XPS, and TEM. By degradation of methylene blue, we investigated the optimal doping amount and calcination temperature of Mo-doped 
$\mathrm{TiO}_{2}$ nanoparticles under a $500 \mathrm{~W}$ xenon lamp and studied its photocatalytic efficiency under natural solar light outdoor.

\section{Experimental}

2.1. Materials. Tetrabutyl titanate $\left(\mathrm{Ti}\left(\mathrm{OC}_{4} \mathrm{H}_{9}\right)_{4}\right)$ was obtained from Tianjin Guangfu Institute of Fine Chemicals (China). Absolute ethyl alcohol $\left(\mathrm{CH}_{3} \mathrm{CH}_{2} \mathrm{OH}\right)$ was obtained from Beijing Chemical Works (China). Ammonium molybdate $\left(\left(\mathrm{NH}_{4}\right)_{6} \mathrm{Mo}_{7} \mathrm{O}_{24} \cdot 4 \mathrm{H}_{2} \mathrm{O}\right)$ was obtained from Tianjin Guangfu Technology Development Co., Ltd. (China). Nitric acid $\left(\mathrm{HNO}_{3}\right)$ was obtained from Xilong Chemical Co., Ltd. (China). All reagents were of analytical grade.

2.2. Preparation of Photocatalysts. Mo-doped $\mathrm{TiO}_{2}$ nanoparticles were synthesized by sol-gel method. Under continuous stirring, different amounts of ammonium molybdate were previously dissolved in a mixture solution consisting of $48.2 \mathrm{~mL}$ ethanol, $6 \mathrm{~mL}$ deionized water, and $0.6 \mathrm{~mL}$ nitric acid to form the mixture solution $\mathrm{A}$. Then solution $\mathrm{A}$ was added dropwise into the mixture solution $\mathrm{B}$ containing $21.3 \mathrm{~mL}$ tetrabutyl titanate and $48.2 \mathrm{~mL}$ ethanol. The obtained homogeneous solution was magnetically stirred continuously for $1 \mathrm{~h}$ to form a gel and subsequently aged at room temperature for $24 \mathrm{~h}$. The gel was then dried in an oven at $60^{\circ} \mathrm{C}$ until a dry gel was obtained. The dry gel was calcined in a muffle furnace at $300,450,550$, and $650^{\circ} \mathrm{C}$, respectively, to obtain Mo-doped $\mathrm{TiO}_{2}$ nanoparticles. For comparison, the samples of pure $\mathrm{TiO}_{2}$ and Mo-doped $\mathrm{TiO}_{2}$ were prepared by similar procedures. Atomic ratios of $\mathrm{Mo}$ in the samples were $0.5 \%$, $1.0 \%, 2.0 \%$, and $3.5 \%$, respectively. The as-prepared samples were denoted as $\operatorname{MT}(n t)$, where hereafter $n$ represented the atomic ratio of $\mathrm{Mo} / \mathrm{Ti}(\%)$ and $t$ represented calcination temperature $\left({ }^{\circ} \mathrm{C}\right)$. The undoped $\mathrm{TiO}_{2}$ was denoted as $\mathrm{T}(t)$ and used as a reference.

2.3. Characterizations. The crystal structures were examined with a powder X-ray diffraction (XRD) (BRUKER D8 ADVANCE, $\mathrm{Cu} \mathrm{K} \alpha, \lambda=1.54056 \AA$ ). UV-visible reflectance spectra (UV/Vis DSC) for the samples were collected on a UV-visible spectrometer (UV-2550 UV/vis Spectrometer, Shimadzu). X-ray photoelectron spectra (XPS) analysis was conducted through an X-ray photoelectron spectrometer (Thermo ESCALAB 250) with an $\mathrm{Al} \mathrm{K \alpha}(1486.7 \mathrm{eV}) \mathrm{X}$ ray source. Transmission electron microscopy (TEM) was recorded on a FECNAI F20 microscope.

2.4. Photocatalytic Degradation Experiment. The photocatalytic activity experiment of prepared nanoparticles was conducted in a quartz glass $(\Phi 70 * 80 \mathrm{~mm})$. In each experiment, $0.2 \mathrm{~g}$ photocatalyst was added to $400 \mathrm{~mL}$ of $20 \mathrm{mg} \cdot \mathrm{L}^{-1}$ methylene blue solution. Two kinds of light source were used: a $500 \mathrm{~W}$ xenon lamp and natural solar light outdoor (July 24, 2014; $\mathrm{N} 43.88^{\circ}, \mathrm{E} 125.32^{\circ}$ ). Every $30 \mathrm{~min}, 5 \mathrm{~mL}$ suspension was sampled, centrifuged, and tested by UNICO 2100 visible spectrophotometer at $664 \mathrm{~nm}$.
TABLE 1: Crystallite parameters of $\mathrm{TiO}_{2}$ with different Mo doping amounts.

\begin{tabular}{lccccc}
\hline Samples & $\begin{array}{r}\text { Anatase in } \\
\mathrm{TiO}_{2} / \%\end{array}$ & \multicolumn{2}{c}{ Crystalline size/nm } & \multicolumn{2}{c}{ Lattice distortion } \\
& 44.4 & 29.8 & 36.2 & 0.30 & 0.22 \\
\hline $\mathrm{T}(550)$ & 78.3 & 23.5 & 33.3 & 0.38 & 0.24 \\
$\mathrm{MT}(0.5550)$ & 82.7 & 20.2 & 32.4 & 0.42 & 0.25 \\
$\mathrm{MT}(1.0550)$ & 100 & 16.6 & & 0.54 & \\
$\mathrm{MT}(2.0550)$ & 100 & & 0.61 & \\
$\mathrm{MT}(3.5550)$ & 100 & 14.6 & & &
\end{tabular}

\section{Results and Discussion}

3.1. XRD Analysis. Figure 1(a) shows XRD patterns of samples calcined at $550^{\circ} \mathrm{C}$ with different Mo doping amounts. The XRD peaks at $2 \theta=25.6^{\circ}$ (101) and $2 \theta=27.7^{\circ}$ (110) were often taken as the characteristic peaks of anatase and rutile crystal phase, respectively [16]. The intensities of anatase peaks increased and the width of peaks became broader with Mo doping amount increasing.

The phase contents of the samples were calculated by $x_{\mathrm{A}}=1 /\left(1+1.26 I_{\mathrm{R}} / I_{\mathrm{A}}\right)$ where $x_{\mathrm{A}}$ is the fraction of anatase phase and $I_{\mathrm{A}}$ and $I_{\mathrm{R}}$ are the intensities of the anatase (101) and rutile (110) diffraction peaks, respectively [17]. The crystallite sizes were calculated with Scherrer formula $D=K \lambda / \beta \cos \theta$ where $D$ is the average crystallite size in angstroms, $K$ is a dimensionless constant ( 0.89 here), $\lambda$ is the wavelength of the $\mathrm{X}$-ray radiation $(\mathrm{Cu} \mathrm{K} \alpha=0.15406 \mathrm{~nm}), \beta$ is the full width at half maximum (FWHM). The lattice distortions were attained from $\varepsilon=\beta / 4 \operatorname{tg} \theta$ in which $\varepsilon$ is lattice distortion and $\theta$ is the diffraction angle [18]. Results were listed in Table 1.

It could be seen that crystallite size decreased and anatase $\mathrm{TiO}_{2}$ increased with Mo doping amount increasing. Conclusions could be derived that the Mo doping inhibited the growth of crystallite size and suppressed the transformation from anatase to rutile of $\mathrm{TiO}_{2}$. It was noted that there was no detected $\mathrm{MoO}_{3}$ phase. This might be ascribed to the incorporation of $\mathrm{Mo}^{6+}$ ion into the $\mathrm{TiO}_{2}$ lattice. The ionic radius of $\mathrm{Mo}^{6+}$ is $0.062 \mathrm{~nm}$, and that of $\mathrm{Ti}^{4+}$ is $0.068 \mathrm{~nm}$ [19]. Because of the similarity in their ionic sizes, Mo could easily be incorporated into the $\mathrm{TiO}_{2}$ lattice, resulting in a narrower energy gap, which could be observed in the following UVvis spectroscopy. Another consequence was that Mo doping increased lattice distortion of samples, which was confirmed by data in Table 1. Generally, smaller crystallite was attributed to greater lattice distortion caused by larger doping amount, which would also enhance the concentration of lattice defects and thus precipitate carrier recombination [20]. This implied that excessive doping, though more carriers could be generated due to smaller energy gap, would exert a negative effect on photocatalytic properties.

Figure 1(b) shows XRD patterns of samples with different calcination temperatures. With calcination temperature increasing, the diffraction peaks became sharper and stronger due to the growth of anatase crystallites. Obviously, the phase transformation from anatase to rutile occurred between $550^{\circ} \mathrm{C}$ and $650^{\circ} \mathrm{C}$. The average crystallite sizes at 300,450 , 


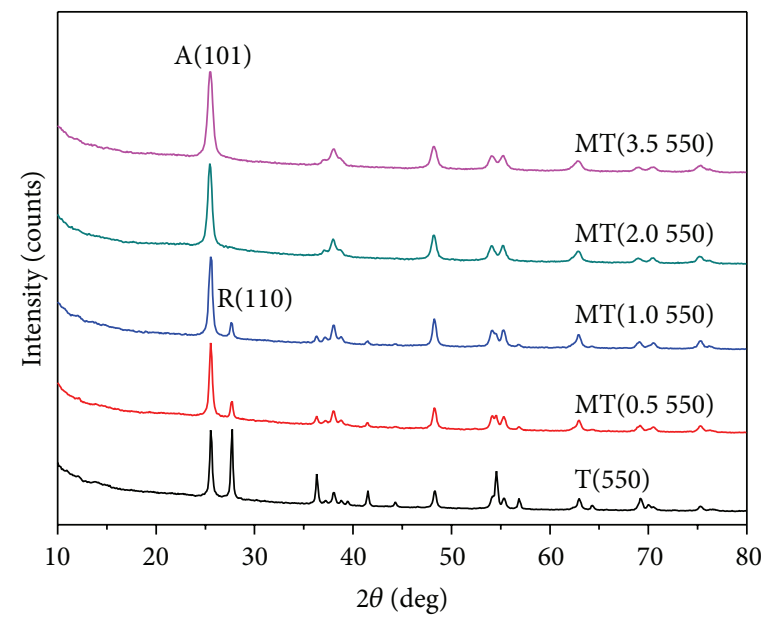

A: anatase

$\mathrm{R}$ : rutile

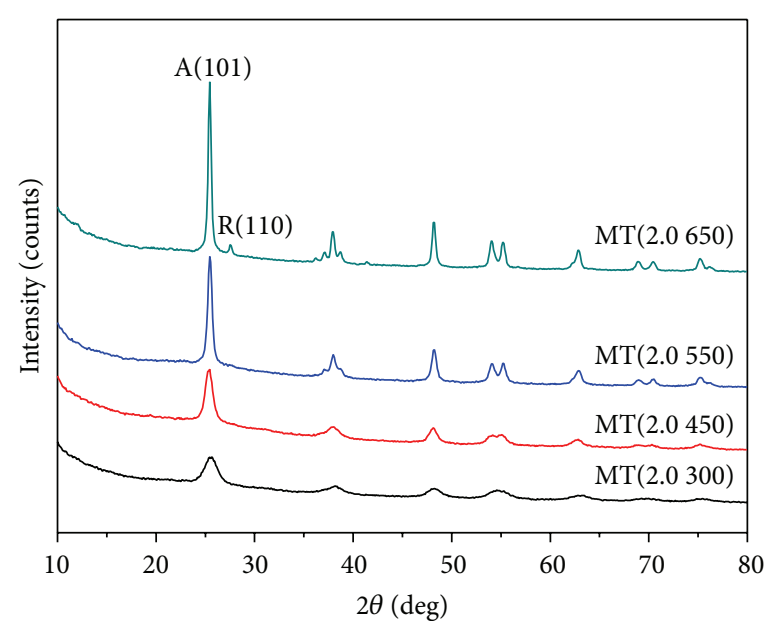

A: anatase

R: rutile

(a)

(b)

FIGURE 1: XRD patterns of samples: (a) MT(550) with different Mo doping amounts; (b) MT(2.0) with different calcination temperatures.

TABLE 2: The band gap energies of samples with different Mo doping amounts.

\begin{tabular}{lcc}
\hline Sample & $\lambda(\mathrm{nm})$ & $E_{g}(\mathrm{eV})$ \\
\hline $\mathrm{T}(550)$ & 407.09 & 3.05 \\
$\mathrm{MT}(0.5550)$ & 411.84 & 3.01 \\
$\mathrm{MT}(1.0550)$ & 421.46 & 2.94 \\
$\mathrm{MT}(2.0550)$ & 454.18 & 2.73 \\
MT(3.5 550) & 444.56 & 2.79 \\
\hline
\end{tabular}

550 , and $650^{\circ} \mathrm{C}$ were $5.3,8.9,16.6$, and $25.7 \mathrm{~nm}$, respectively. It could be observed that the crystallite size increased with temperature increasing, which might be caused by particle agglomeration under high temperature [21].

3.2. UV-Vis DRS Analysis. Figure 2 shows the UV-visible absorption spectra of samples with different Mo doping amounts. It showed that Mo doping caused a notable red shift of the absorption edge, which was beneficial to the photocatalytic activity of $\mathrm{Mo}$-doped $\mathrm{TiO}_{2}$ nanoparticles. By offering more valence electrons which could be incited easily into free carriers by photons, Mo doping introduced a donor level under the conduction band of $\mathrm{TiO}_{2}$, leading to a narrower band gap [20]. To MT(3.5 550), however, the absorption edge moved inversely to the shorter wavelength range. This phenomenon was a typical consequence of quantum effect and could be explained as follows: as crystallite size fell into nanoscale, the movement of electrons would be confined more intensively, resulting in the differentiation near the Fermi level and broaden the band gap [22]. The band gap was calculated by $E_{g}=1240 / \lambda$ where $E_{g}(\mathrm{eV})$ is the band gap and $\lambda(\mathrm{nm})$ is the wavelength of the absorption edge in the spectrum [23]. The wavelength of the absorption edge and the calculated band gap of samples were listed in Table 2 .

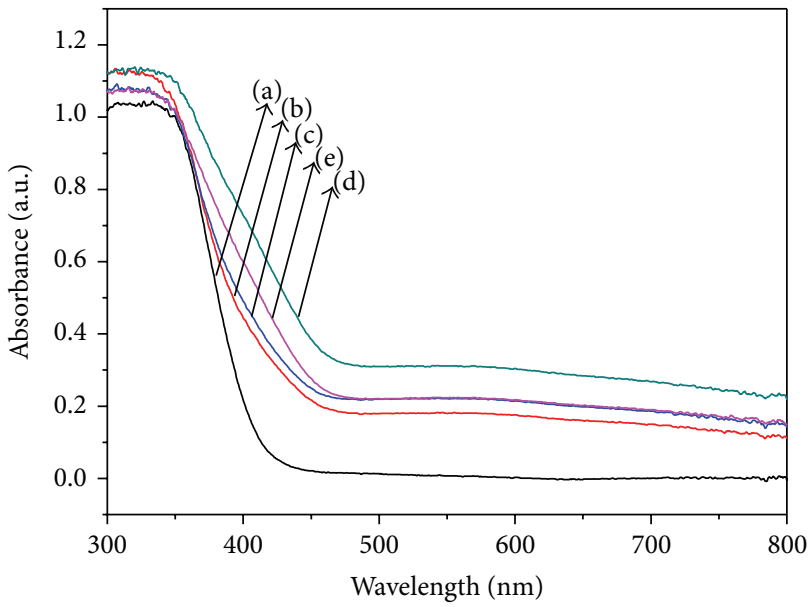
(a) $\mathrm{T}(550)$
(d) $\operatorname{MT}(2.0550)$
(b) $\mathrm{MT}(0.5550)$
(e) $\mathrm{MT}(3.5550)$
(c) $\mathrm{MT}(1.0550)$

FIGURE 2: UV-visible absorption of samples with different Mo doping amounts.

It could be seen that when Mo doping amount increased from 0 to $2.0 \%$, the band gap decreased from $3.05 \mathrm{eV}$ to $2.73 \mathrm{eV}$. But with Mo doping amount further increasing, the band gap increased to $2.79 \mathrm{eV}$, which corresponded to the blue shift of absorption edge as discussed above. Therefore, it could be concluded that an appropriate amount of Mo could effectively shorten the energy of $\mathrm{TiO}_{2}$ while excessive Mo might have the opposite effect.

3.3. XPS Analysis. The XPS spectra of T(550) and MT(2.0 550) were measured. As shown in Figure 3(a), the peaks located at binding energy of $458.4 \mathrm{eV}$ and $463.9 \mathrm{eV}$ corresponded to $\mathrm{Ti} 2 \mathrm{p}_{3 / 2}$ and $\mathrm{Ti} 2 \mathrm{p}_{1 / 2}$ of $\mathrm{TiO}_{2}$, respectively, which 


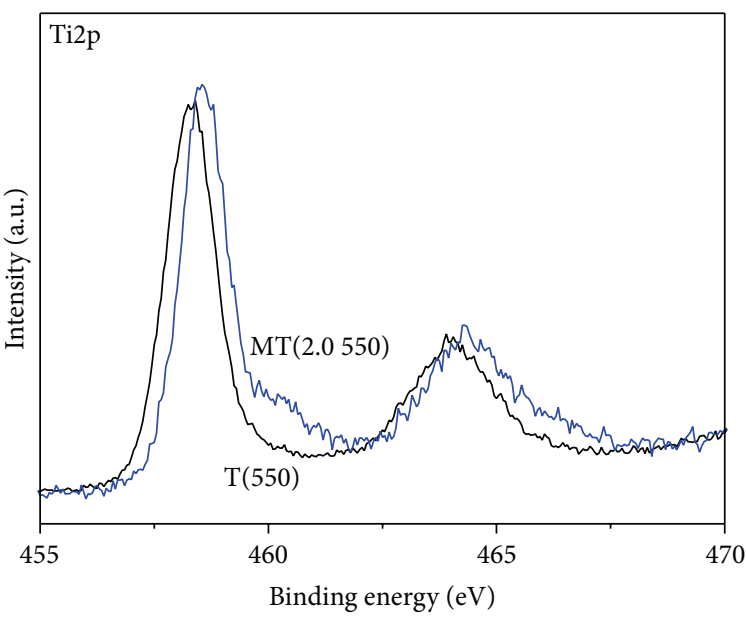

(a)

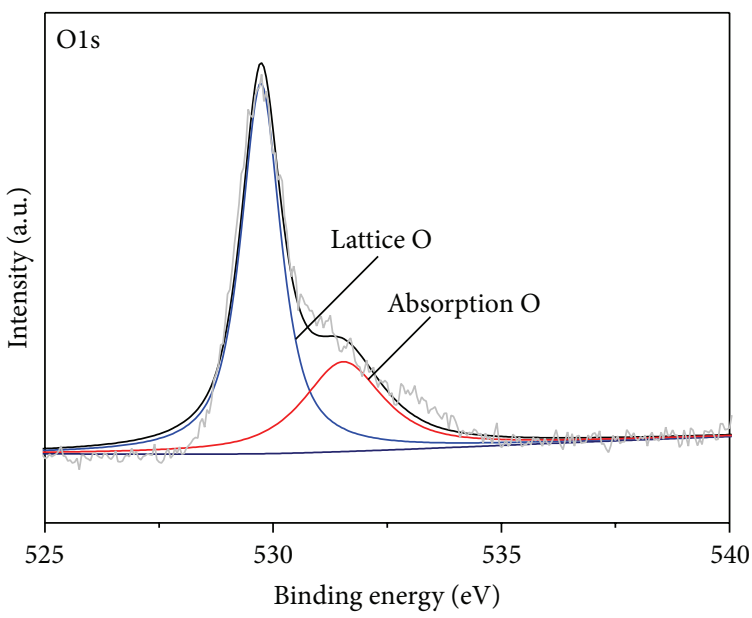

(c)

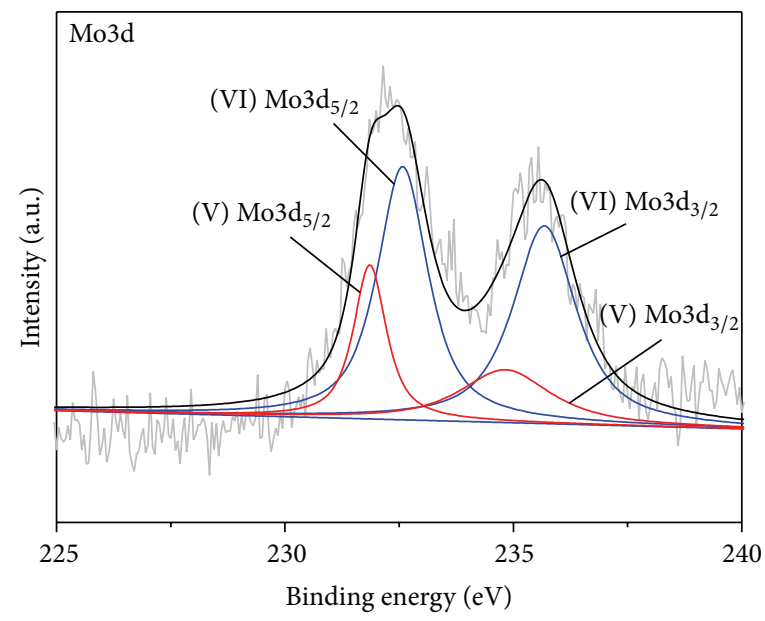

(b)

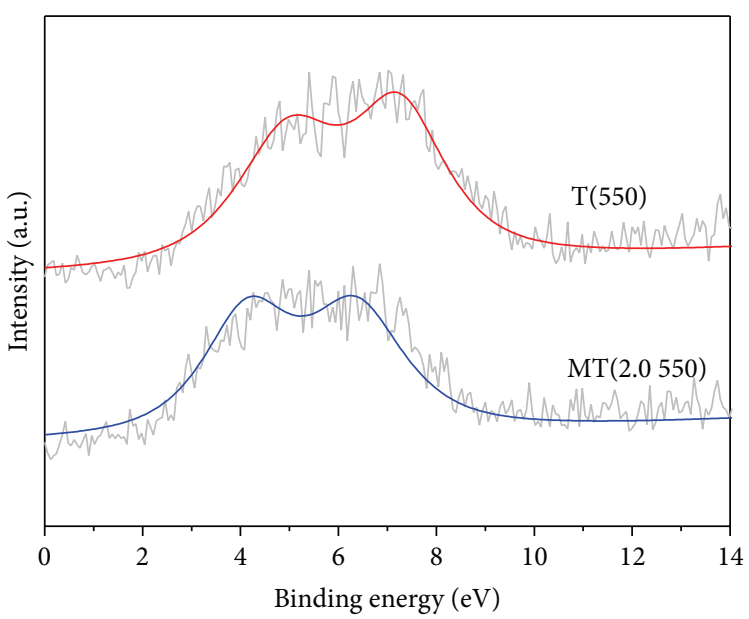

(d)

Figure 3: XPS spectra of samples: (a) Ti2p of T(550) and MT(2.0 550); (b) Mo3d of MT(2.0 550); (c) O1s of MT(2.0 550); (d) valance band spectra of T(550) and MT(2.0 550).

TABLE 3: Solar light intensity in the experiment.

\begin{tabular}{|c|c|c|c|c|c|c|c|c|c|c|c|}
\hline Time/min & 0 & 30 & 60 & 90 & 120 & 150 & 180 & 210 & 240 & 270 & 300 \\
\hline Intensity/Lux & 35000 & 37000 & 47000 & 42000 & 47000 & 47500 & 48000 & 38000 & 42500 & 40000 & 27000 \\
\hline
\end{tabular}

were consistent with the values of $\mathrm{Ti}^{4+}$ in $\mathrm{TiO}_{2}$ lattice [24]. For MT(2.0 550), the binding energies of Ti2 $\mathrm{p}_{3 / 2}$ and $\mathrm{Ti} 2 \mathrm{p}_{1 / 2}$ were $458.55 \mathrm{eV}$ and $464.25 \mathrm{eV}$, respectively; a few right shifts were caused by Mo doping, which might be an indication that molybdenum atoms indeed substituted titanium atoms in the lattice.

Mo3d $d_{5 / 2}$ and $M o 3 d_{3 / 2}$ peaks of MT(2.0 550) are shown in Figure 3(b). The peaks located at $232.6 \mathrm{eV}$ and $235.7 \mathrm{eV}$ corresponded to the feature of $\mathrm{Mo}^{6+}$, while peaks located at $231.8 \mathrm{eV}$ and $234.8 \mathrm{eV}$ corresponded to $\mathrm{Mo}^{5+}$ [25]. No $\mathrm{Mo}^{4+}$ peak was observed, indicating that the main valances of molybdenum in the samples were +6 and +5 . From the ratio of peak area, it could be obtained that the atomic percentage of $\mathrm{Mo}^{6+}$ and $\mathrm{Mo}^{5+}$ would be $72.2 \%$ and $27.8 \%$, respectively. That was as follows: most doped Mo ions existed as $\mathrm{Mo}^{6+}$ ions in $\mathrm{TiO}_{2}$ lattice, but a small part of Mo ions existed as $\mathrm{Mo}^{5+}$ ions. The presence of $\mathrm{Mo}^{5+}$ ions signified no adequate oxygen in $\mathrm{TiO}_{2}$ lattice to support Mo being as complemented oxidation state of $\mathrm{Mo}^{6+}$ ions. So, the existence of $\mathrm{Mo}^{5+}$ ions also implied that $\mathrm{MT}(2.0$ 550) was in oxygen deficiency state (as one titanium atom needed two $\mathrm{O}$ atoms but one molybdenum atom needed three $\mathrm{O}$ atoms). The surface deficiency of $\mathrm{O}$ could be complemented by adsorbing more oxygen, which was beneficial to photocatalytic degradation.

XPS spectrum of the O1s of MT(2.0 550) is given in Figure 3(c). The O1s spectrum could be decomposed into two peaks. The peak at $529.7 \mathrm{eV}$ was assigned to crystal lattice oxygen $\left(\mathrm{O}_{L}\right)$, while the peak located at $531.5 \mathrm{eV}$ could be attributed to adsorbed oxygen $\left(\mathrm{O}_{H}\right)$ [26]. The $\mathrm{O}_{L}$ was mainly attributed to the contribution of $\mathrm{Ti}-\mathrm{O}$ in $\mathrm{TiO}_{2}$ crystal lattice, 


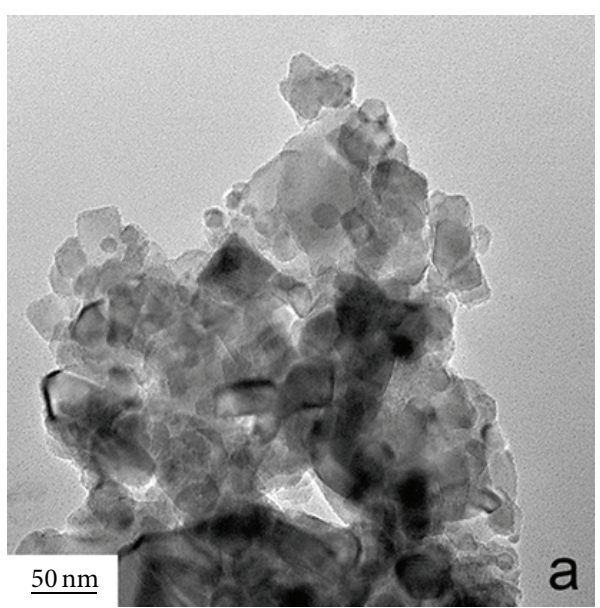

(a)

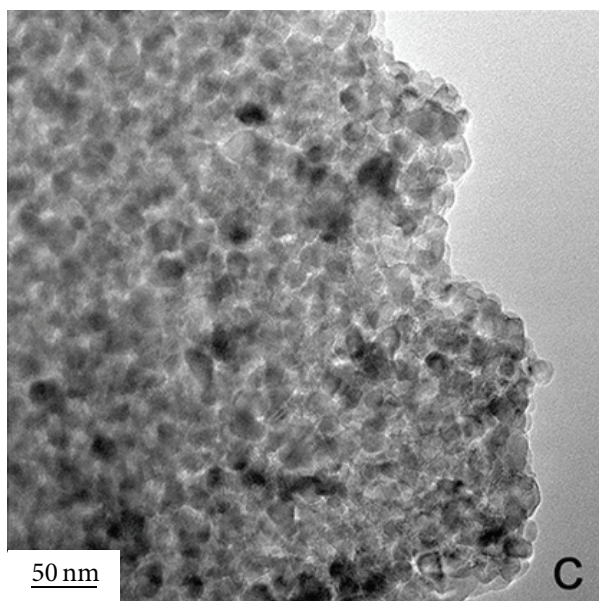

(c)

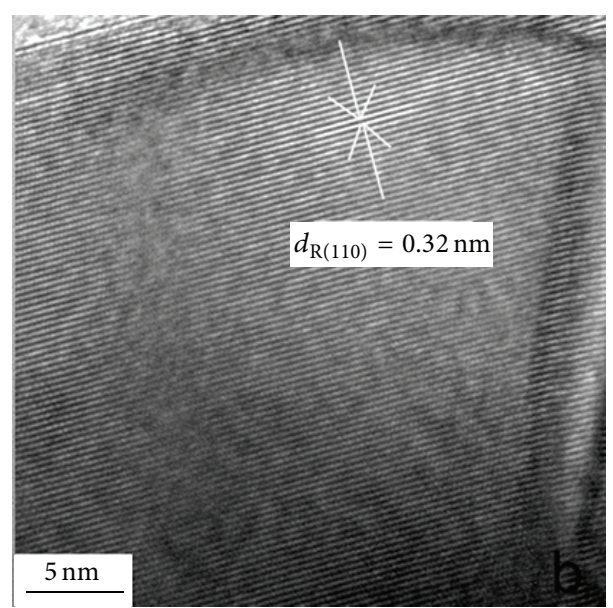

(b)

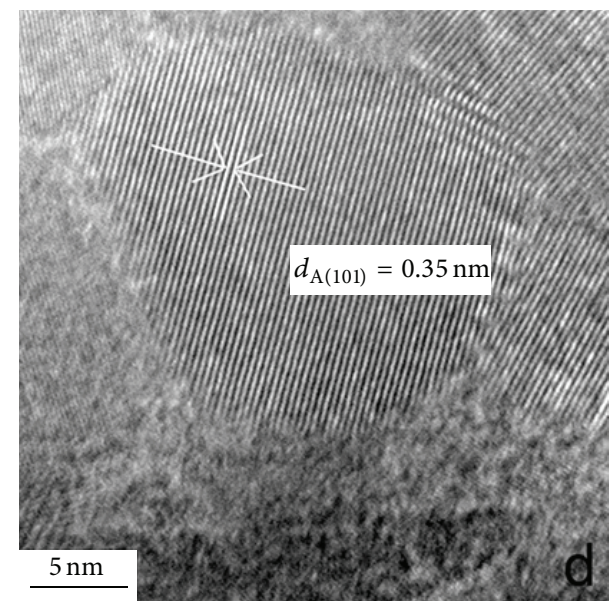

(d)

Figure 4: TEM images of samples: (a, b) T(550); (c, d) MT(2.0 550).

and the $\mathrm{O}_{H}$ was ascribed to lattice distortion as well as porous structure brought about by Mo doping.

According to the valance band (VB) spectra in Figure 3(d), the VB maxima of $\mathrm{T}(550)$ and $\mathrm{MT}(2.0550)$ were $3.04 \mathrm{eV}$ and $2.73 \mathrm{eV}$, respectively. It indicated that Mo doping could narrow the band gap and extend the absorption edge of $\mathrm{TiO}_{2}$ towards visible light, which was consistent with the UV-vis spectroscopy.

3.4. TEM Analysis. Figure 4 showed the microstructures of $\mathrm{T}(550)$ and MT(2.0 550). It could be seen that MT(2.0 550) showed a better dispersion than T(550). All the samples consisted of highly crystalline and compact nanoparticles. For MT(2.0 550), a fine particulate morphology in porous structure could be observed. Figures 4(a) and 4(b) revealed that there were different kinds of crystalline $\mathrm{TiO}_{2}$. In Figure 4(b), it could be seen that the measured lattice spacing of T(550) was $0.32 \mathrm{~nm}$, which was in coincidence with the spacing distance of (110) plane of rutile $\mathrm{TiO}_{2}$ [27]. In Figure 4(d), it is indicated that in the $\mathrm{MT}(2.0550)$ there existed a lattice spacing $(0.35 \mathrm{~nm})$ which was anatase $\mathrm{TiO}_{2}$ [27]. So both the XRD and TEM observations presented the coincident results and showed that $\mathrm{MT}(2.0$ 550) was nanocrystalline anatase $\mathrm{TiO}_{2}$. These results also provided evidence that the Mo doping suppressed the formation of the rutile $\mathrm{TiO}_{2}$ and inhibited the agglomeration of $\mathrm{TiO}_{2}$.

3.5. Photocatalytic Activity. Figure 5 shows photocatalytic degradation of as-prepared photocatalysts with different Mo doping amounts. It could be seen that with Mo doping amount increasing from 0 to $2.0 \%$, the degradation rate of methylene blue increased by $36 \%$, which indicated that Mo was doped into $\mathrm{TiO}_{2}$ lattice and enhanced the photocatalytic activity. However, with Mo doping amount further increasing to $3.5 \%$, the degradation efficiency decreased, which was still better than that of $\mathrm{T}(550), \mathrm{MT}(0.5550)$, and $\mathrm{MT}(1.0$ 550) samples. This could be ascribed to the fact that the concentration of holes on the valence band increased with $\mathrm{Mo}^{6+}$ ions increasing and excessive $\mathrm{Mo}^{6+}$ ions would cause the carriers recombination. As a result, the recombination of generated electron/hole pair exceeded the carrier transition to the surface of photocatalysts. Once the concentration of 


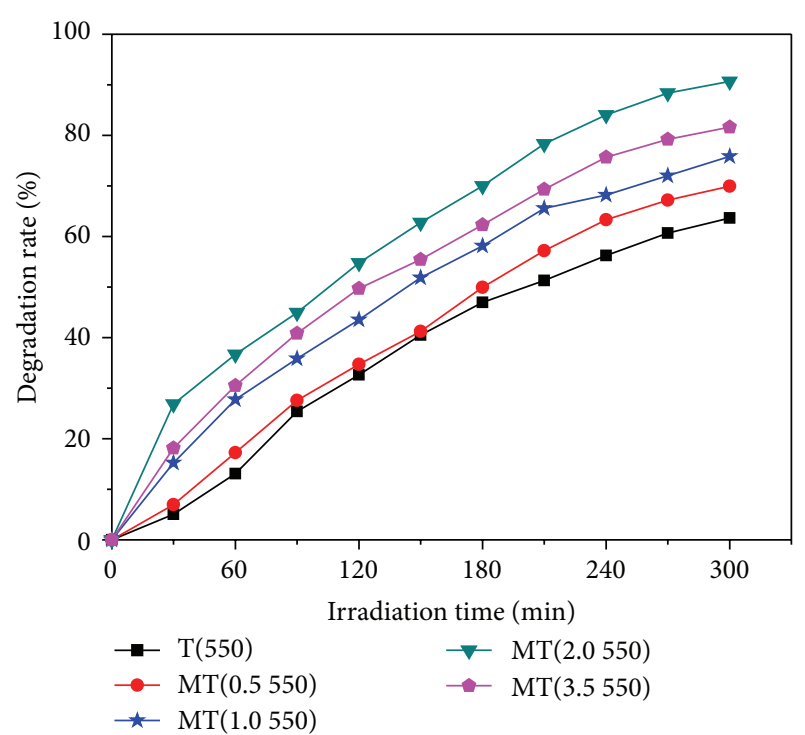

FIGURE 5: Photocatalytic degradation of samples with different Mo doping amounts.

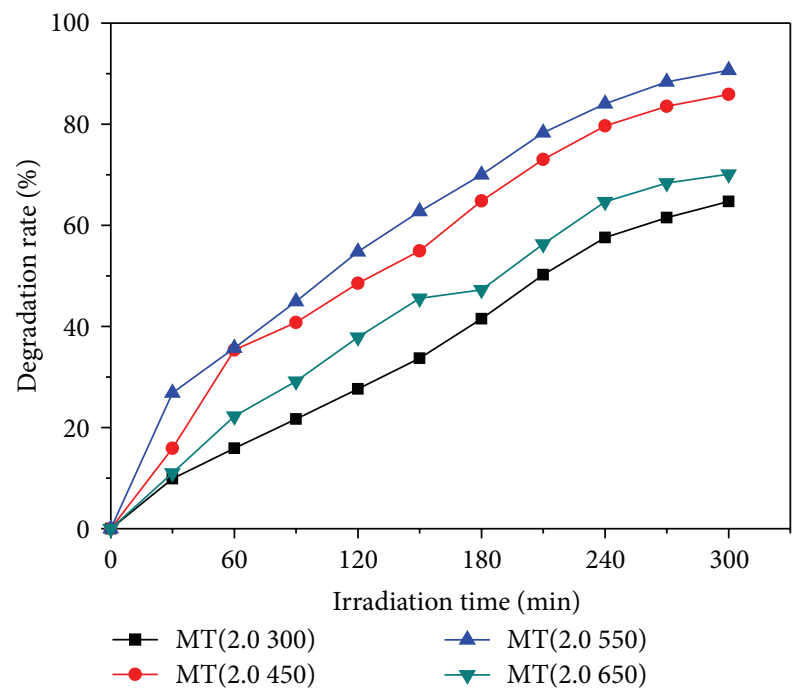

Figure 6: Photocatalytic degradation of samples with different calcination temperatures.

Mo was beyond an optimum quantity, $\mathrm{Mo}^{6+}$ ions role as a carrier recombination center would counteract its role of trapping carriers and prolonging carrier lifetime [28]. So a decrease of photocatalytic activity was observed.

Figure 6 shows the results of photocatalytic degradation of samples with different calcination temperatures. It indicated that calcination temperature had great influence on the structure of photocatalyst. With the calcination temperature increasing from $300^{\circ} \mathrm{C}$ to $550^{\circ} \mathrm{C}$, the degradation effect increased. However, when the calcination temperature reached $650^{\circ} \mathrm{C}$, the degradation effect decreased, which might be related to the crystallite size and the ratio of anatase and rutile $\mathrm{TiO}_{2}$ in the samples. High temperature caused particle agglomeration and decreased the surface

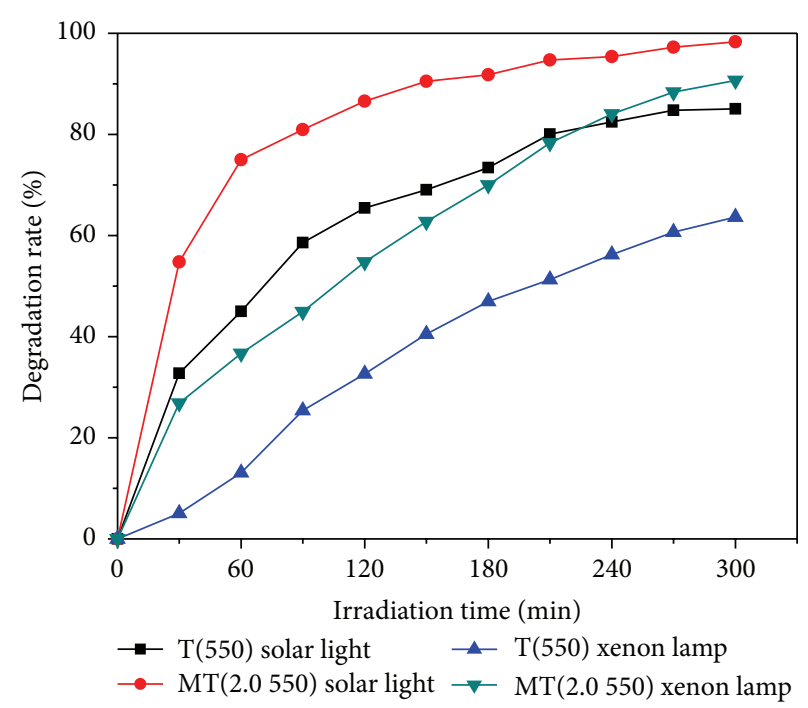

Figure 7: Photocatalytic degradation of MT(2.0 550) under different light sources (7000 Lux xenon lamp, solar light (Table 3)).

area of photocatalysts, which could also affect the efficiency. According to Figures 5 and 6, conclusions could be derived that the optimum Mo doping amount and the calcination temperature were $2.0 \%$ and $550^{\circ} \mathrm{C}$, respectively.

Due to different band gap corresponding to different excitation wavelengths, light utilization of photocatalysts on different wave bands was not the same. Two kinds of light source were used in the experiments, respectively. The results are shown in Figure 7. It could be observed that MT(2.0 550) had a better performance than T(550) under both solar light and xenon lamp. It might be ascribed to the fact that Mo ions could capture the photogenerated carriers to prolong the lifetime of carriers or quicken the separation of carriers [29], which enhanced the photocatalytic activity and improved the utilization of solar light. Mo-doped $\mathrm{TiO}_{2}$ photochemical catalysis was shown to be an efficient method for degradation of methylene blue under visible light, especially under solar light.

\section{Conclusions}

Undoped and Mo-doped $\mathrm{TiO}_{2}$ nanoparticles were successfully synthesized by sol-gel method. XRD results showed that crystallite size decreased and anatase $\mathrm{TiO}_{2}$ increased with Mo doping amount increasing. Mo doping inhibited the growth of crystallite size and suppressed the transformation from anatase to rutile of $\mathrm{TiO}_{2}$. For Mo-doped $\mathrm{TiO}_{2}$, the phase transformation from anatase to rutile occurred between $550^{\circ} \mathrm{C}$ and $650^{\circ} \mathrm{C}$. The crystallite size increased with temperature increasing, which might be caused by particle agglomeration under high temperature. UV-vis DRS indicated the optical absorption edges of Mo-doped samples shifted to longer wavelength regions. Ti2p, Mo3d, and O1s of Mo-doped $\mathrm{TiO}_{2}$ were detected by XPS, which suggested that molybdenum atom was doped into $\mathrm{TiO}_{2}$ and most doped $\mathrm{Mo}$ ions existed as $\mathrm{Mo}^{6+}$ ions in $\mathrm{TiO}_{2}$ lattice. All 
the samples consisted of highly crystalline and compact nanoparticles. Mo-doped $\mathrm{TiO}_{2}$ photochemical catalysis was shown to be an efficient method for degradation of methylene blue under visible light, especially under solar light. When the calcination temperature was $550^{\circ} \mathrm{C}$ and the Mo doping amount was $2.0 \%$, the Mo-doped $\mathrm{TiO}_{2}$ sample exhibited the highest photocatalytic activity.

\section{Conflict of Interests}

The authors declare that there is no conflict of interests regarding the publication of this paper.

\section{Acknowledgments}

This work was supported by the National Natural Science Foundation of China (no. 51308252), Jilin Province Science and Technology Development Plans (no. 20130101091JC), and the analysis and testing foundation of Jilin University and Changchun Technology Innovation Fund (no. 2009086).

\section{References}

[1] J. Zhong, J. Li, J. Zeng et al., "Enhanced photocatalytic activity of $\mathrm{In}_{2} \mathrm{O}_{3}$-decorated $\mathrm{TiO}_{2}$," Applied Physics A: Materials Science and Processing, vol. 115, no. 4, pp. 1231-1238, 2014.

[2] M. E. Hassan, L. Cong, G. Liu, D. Zhu, and J. Cai, "Synthesis and characterization of C-doped $\mathrm{TiO}_{2}$ thin films for visible-lightinduced photocatalytic degradation of methyl orange," Applied Surface Science, vol. 294, pp. 89-94, 2014.

[3] J.-G. Huang, X.-G. Zhao, M.-Y. Zheng, S. Li, Y. Wang, and X.-J. Liu, "Preparation of $\mathrm{N}$-doped $\mathrm{TiO}_{2}$ by oxidizing $\mathrm{TiN}$ and its application on phenol degradation," Water Science and Technology, vol. 68, no. 4, pp. 934-939, 2013.

[4] X. Yu, T. Hou, X. Sun, and Y. Li, "The influence of defects on Modoped $\mathrm{TiO}_{2}$ by first-principles studies," ChemPhysChem, vol. 13, no. 6, pp. 1514-1521, 2012.

[5] M. Khan, J. Xu, N. Chen, and W. Cao, "Electronic and optical properties of pure and Mo doped anatase $\mathrm{TiO}_{2}$ using GGA + U and GGAU calculations," Physica B: Condensed Matter, vol. 407, no. 17, pp. 3610-3616, 2012.

[6] M. Zhou, J. Yu, B. Cheng, and H. Yu, "Preparation and photocatalytic activity of Fe-doped mesoporous titanium dioxide nanocrystalline photocatalysts," Materials Chemistry and Physics, vol. 93, no. 1, pp. 159-163, 2005.

[7] L. Cao, D. Wang, L. Xu, and X. Li, "First-principles study on the synergistic effects of Mo-C codoped anatase $\mathrm{TiO}_{2}$," Solid State Communications, vol. 185, pp. 5-9, 2014.

[8] K. T. Ranjit and B. Viswanathan, "Synthesis, characterization and photocatalytic properties of iron-doped $\mathrm{TiO}_{2}$ catalysts," Journal of Photochemistry and Photobiology A: Chemistry, vol. 108, no. 1, pp. 79-84, 1997.

[9] Z. Liu, B. Guo, L. Hong, and H. Jiang, "Preparation and characterization of cerium oxide doped $\mathrm{TiO}_{2}$ nanoparticles," Journal of Physics and Chemistry of Solids, vol. 66, no. 1, pp. 161$167,2005$.

[10] P. Bouras, E. Stathatos, and P. Lianos, "Pure versus metalion-doped nanocrystalline titania for photocatalysis," Applied Catalysis B: Environmental, vol. 73, no. 1-2, pp. 51-59, 2007.
[11] S. Klosek and D. Raftery, "Visible light driven V-doped $\mathrm{TiO}_{2}$ photocatalyst and its photooxidation of ethanol," Journal of Physical Chemistry B, vol. 105, pp. 2815-2819, 2002.

[12] L. G. Devi and B. N. Murthy, "Characterization of Mo doped $\mathrm{TiO}_{2}$ and its enhanced photo catalytic activity under visible light," Catalysis Letters, vol. 125, no. 3-4, pp. 320-330, 2008.

[13] C. X. Li, D. Zhang, Z. H. Jiang, Z. P. Yao, and F. Z. Jia, "Mo-doped titania films: preparation, characterization and application for splitting water," New Journal of Chemistry, vol. 35, no. 2, pp. 423429, 2011.

[14] M. Li, J. Zhang, and Y. Zhang, "Electronic structure and photocatalytic activity of N/Mo doped anatase $\mathrm{TiO}_{2}$," Catalysis Communications, vol. 29, pp. 175-179, 2012.

[15] L. G. Devi, B. N. Murthy, and S. G. Kumar, "Photocatalytic activity of $\mathrm{V}^{5+}, \mathrm{Mo}^{6+}$ and $\mathrm{Th}^{4+}$ doped polycrystalline $\mathrm{TiO}_{2}$ for the degradation of chlorpyrifos under UV/solar light," Journal of Molecular Catalysis A: Chemical, vol. 308, no. 1-2, pp. 174-181, 2009.

[16] H. Yang, X. Li, A. Wang, Y. Wang, and Y. Chen, "Photocatalytic degradation of methylene blue by $\mathrm{MoO}_{3}$ modified $\mathrm{TiO}_{2}$ under visible light," Chinese Journal of Catalysis, vol. 35, no. 1, pp. 140147, 2014.

[17] R. A. Spurr, "Quantitative analysis of anatase-rutile mixtures with an X-ray diffractometer," Analytical Chemistry, vol. 29, no. 5, pp. 760-762, 1957.

[18] L. Yin, Q. Zhou, X. Tang, G. Lin, and J. Zhang, "The mechanism of nanocrystalline $\mathrm{TiO}_{2}$ derived by sol-gel process," Journal of Functional Materials, vol. 4, pp. 498-502, 1999.

[19] M. Khan, J. Xu, N. Chen, and W. Cao, "First principle calculations of the electronic and optical properties of pure and (Mo, $\mathrm{N}$ ) co-doped anatase $\mathrm{TiO}_{2}$," Journal of Alloys and Compounds, vol. 513, pp. 539-545, 2012.

[20] S.-Y. Luo, B.-X. Yan, and J. Shen, "Enhancement of photoelectric and photocatalytic activities: $\mathrm{Mo}$ doped $\mathrm{TiO}_{2}$ thin films deposited by sputtering," Thin Solid Films, vol. 522, pp. 361-365, 2012.

[21] S. Hu, A. Wang, X. Li, and H. Löwe, "Hydrothermal synthesis of well-dispersed ultrafine $\mathrm{N}$-doped $\mathrm{TiO}_{2}$ nanoparticles with enhanced photocatalytic activity under visible light," Journal of Physics and Chemistry of Solids, vol. 71, no. 3, pp. 156-162, 2010.

[22] J. C. Yu, W. Ho, Z. Jiang, and L. Zhang, "Effects of Fdoping on the photocatalytic activity and microstructures of nanocrystalline $\mathrm{TiO}_{2}$ powders," Chemistry of Materials, vol. 14, no. 9, pp. 3808-3816, 2002.

[23] N. Sahoo and K. Apparao, "Process-parameter optimization of $\mathrm{Sb}_{2} \mathrm{O}_{3}$ films in the ultraviolet and visible region for interferometric applications," Applied Physics A, vol. 63, no. 2, pp. 195202, 1996.

[24] S.-K. Joung, T. Amemiya, M. Murabayashi, and K. Itoh, "Mechanistic studies of the photocatalytic oxidation of trichloroethylene with visible-light-driven $\mathrm{N}$-doped $\mathrm{TiO}_{2}$ photocatalysts," Chemistry A: European Journal, vol. 12, no. 21, pp. 5526-5534, 2006.

[25] B. Houng, C. C. Liu, and M. T. Hung, "Structural, electrical and optical properties of molybdenum-doped $\mathrm{TiO}_{2}$ thin films," Ceramics International, vol. 39, no. 4, pp. 3669-3676, 2013.

[26] J.-G. Yu, H.-G. Yu, B. Cheng, X.-J. Zhao, J. C. Yu, and W.K. Ho, "The effect of calcination temperature on the surface microstructure and photocatalytic activity of $\mathrm{TiO}_{2}$ thin films prepared by liquid phase deposition," Journal of Physical Chemistry B, vol. 107, no. 50, pp. 13871-13879, 2003. 
[27] Y. D. Hou, X. C. Wang, L. Wu et al., "N-Doped $\mathrm{SiO}_{2} / \mathrm{TiO}_{2}$ mesoporous nanoparticles with enhanced photocatalytic activity under visible-light irradiation," Chemosphere, vol. 72, no. 3 , pp. 414-421, 2008.

[28] S. Wang, L. N. Bai, H. M. Sun, Q. Jiang, and J. S. Lian, "Structure and photocatalytic property of Mo-doped $\mathrm{TiO}_{2}$ nanoparticles," Powder Technology, vol. 244, pp. 9-15, 2013.

[29] Y. Yang, X.-j. Li, J.-t. Chen, and L.-y. Wang, "Effect of doping mode on the photocatalytic activities of $\mathrm{Mo} / \mathrm{TiO}_{2}$," Journal of Photochemistry and Photobiology A: Chemistry, vol. 163, no. 3, pp. 517-522, 2004. 

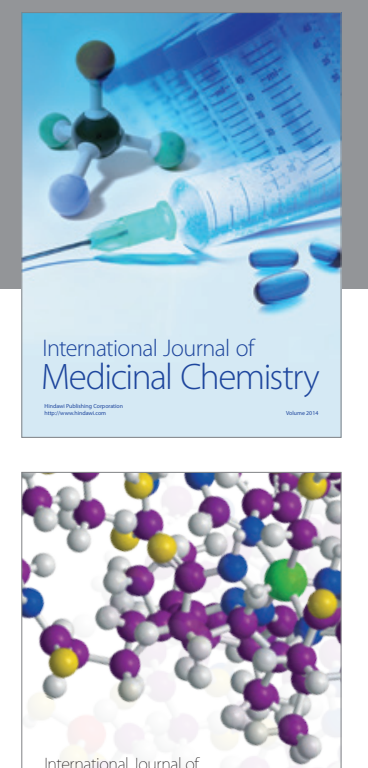

\section{Carbohydrate} Chemistry

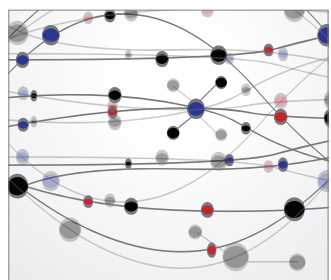

The Scientific World Journal
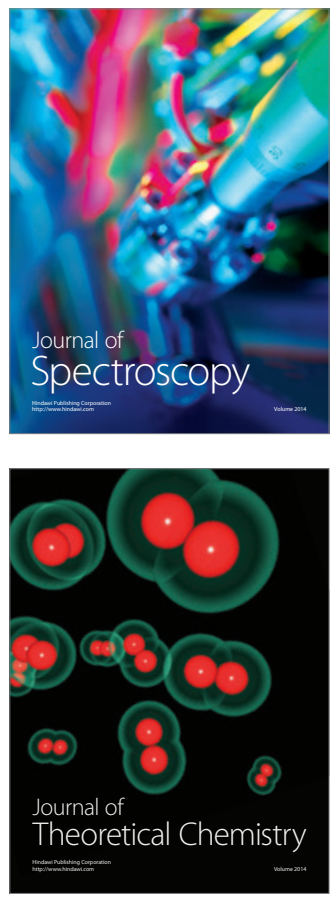
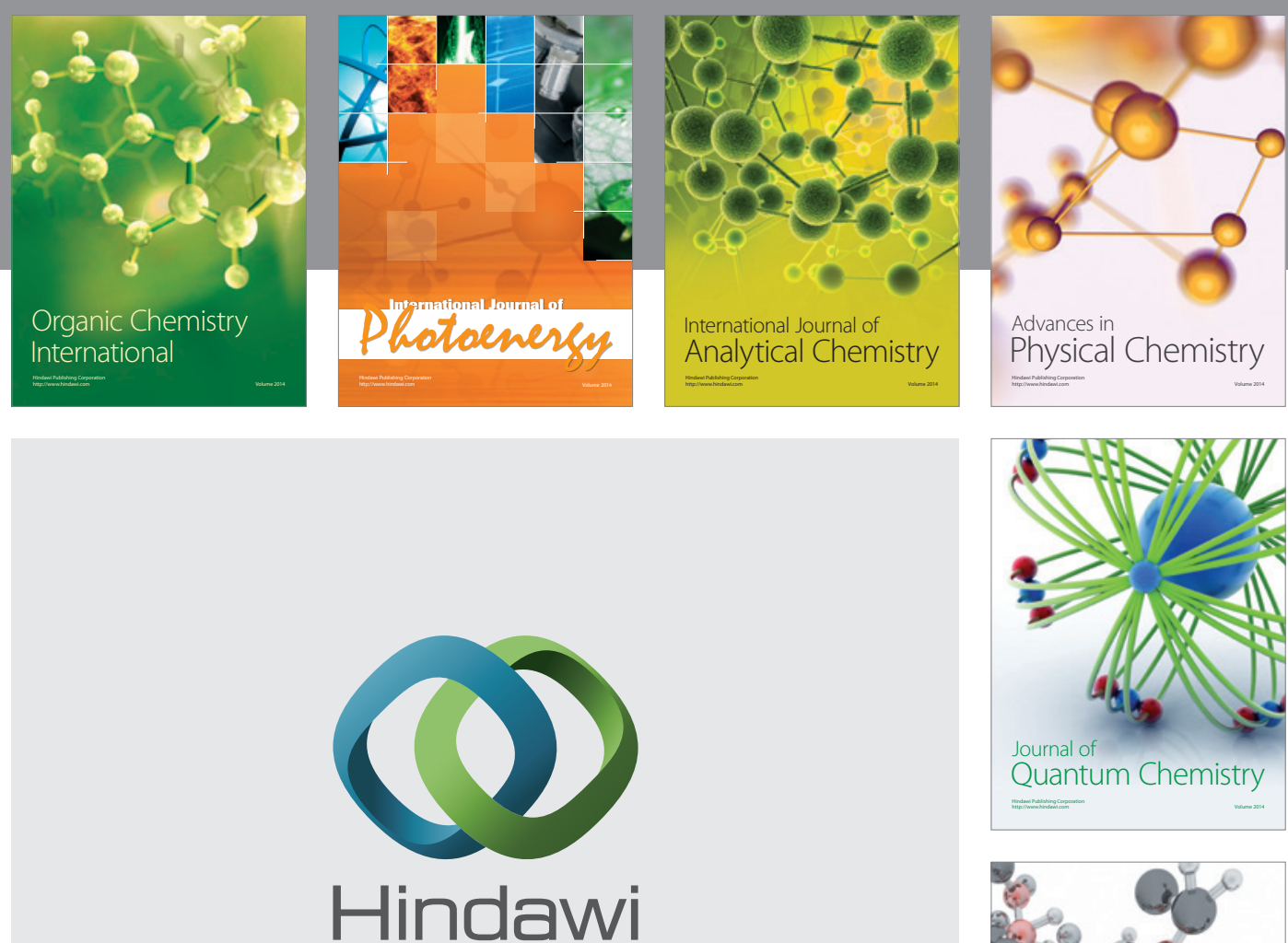

Submit your manuscripts at

http://www.hindawi.com

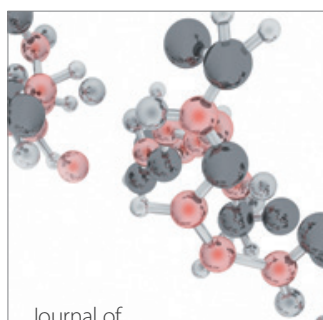

Analytical Methods

in Chemistry

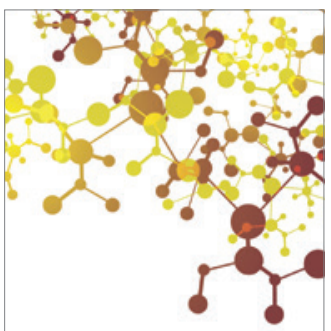

Journal of

Applied Chemistry

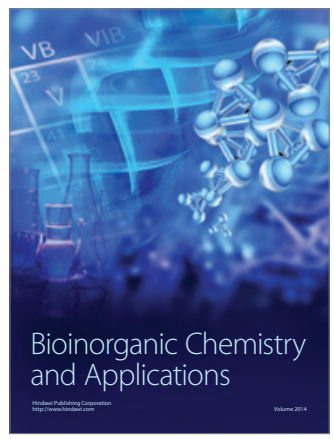

Inorganic Chemistry
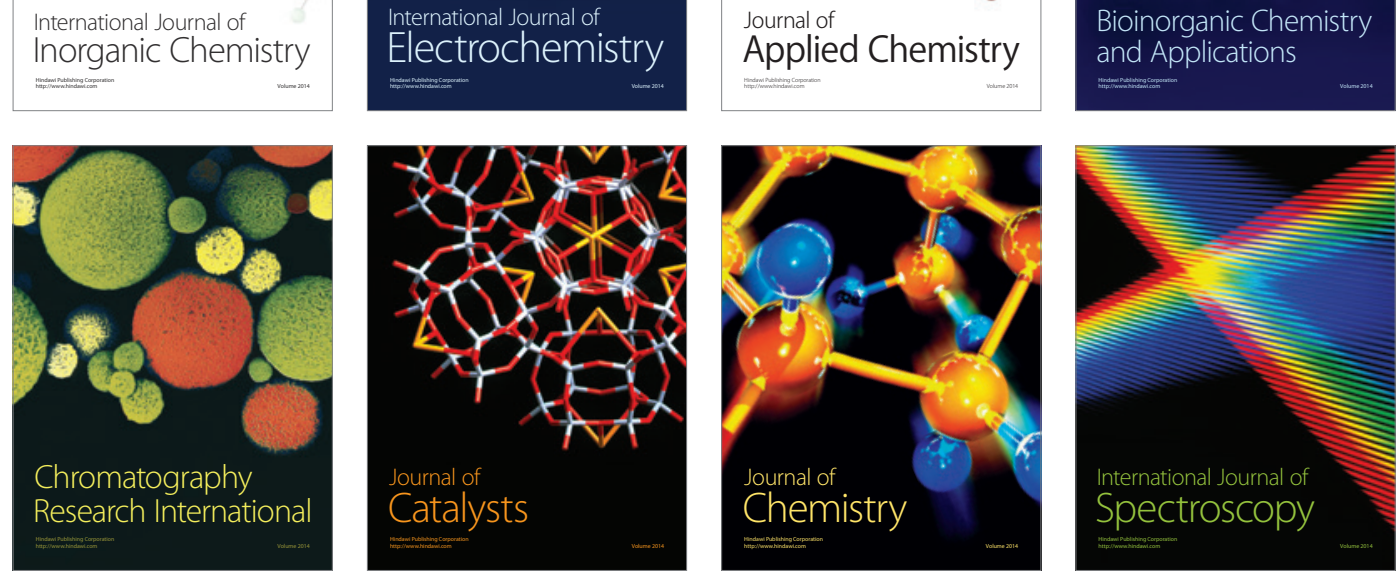